\title{
ANTROPOSENTRISME DALAM ANIMASI PRINCESS MONONOKE KARYA HAYAO MIYAZAKI
}

\author{
Alisca Putri Dirgantari, Yanti Heriyawati, Andang Iskandar \\ Pascasarjana Institut Seni Budaya Indonesia (ISBI) Bandung \\ Jl. Buah-Batu No.212, Cijagra, Lengkong, Kota Bandung 40265 \\ alliscapark@yahoo.com
}

\begin{abstract}
This study analyzes the ethics of anthropocentrism contained in the animated film Princess Mononoke. The destruction of nature contained in the film is done by the antagonists, namely Miss Eboshi, Jiko-Bou, and their followers. The research method used is Roland Barthes' semiotic analysis which looks at three stages of significance, namely denotation, connotation, and myth. The stage of film analysis begins with identifying the form of oppression in the form of the selected scene, then the data is analyzed through the interpretation of denotative and connotative meanings to find myths. The results of this study indicate that this film represents the exploitation and ethics of anthropocentrism towards nature and the Shintoism gods who protect nature so that it triggers conflict between humans and the gods. The exploitation occurs because the antagonists want to conquer nature and the gods for personal interests and ambitions to gain profit and wealth without thinking about the ethics and moral status of nature, animals and nonhumans in the film Princess Mononoke.
\end{abstract}

Keywords: Anthropocentrism; Exploitation of nature; Animated Film; Princess Mononoke.

\begin{abstract}
ABSTRAK
Penelitian ini menganalisis etika antroposentrisme yang terdapat dalam film animasi Princess Mononoke. Kerusakan alam yang terdapat dalam film dilakukan oleh para tokoh antagonis yaitu Nona Eboshi, Jiko-Bou, dan para pengikut mereka. Metode penelitian yang digunakan analisis semiotika Roland Barthes yang melihat pada tiga tahapan signifikasi yaitu denotasi, konotasi, dan mitos. Tahapan analisis film dimulai dengan mengidentifikasi bentuk penindasan berupa scene yang telah dipilih, kemudian data tersebut dianalisismelalui interpretasi makna denotasi dan konotasi untuk menemukan mitos. Hasil penelitian ini menunjukkan bahwa film ini merepresentasikan terjadinya eksploitasi dan etika antroposentrisme terhadap alam dan dewa-dewa Shintoisme yang menjaga alam sehingga memicu konflik antara manusia dan para dewa. Eksploitasi tersebut terjadi karena para tokoh antagonis ingin menaklukan alam dan dewa-dewa untuk kepentingan dan ambisi pribadi untuk mendapatkan keuntungan dan kekayaan tanpa memikirkan etika dan status moral alam, hewan dan yang non-manusia dalam film Princess Mononoke.
\end{abstract}

Kata Kunci: Antroposentrisme; Eksploitasi alam; Film Animacasi; Princess Mononoke. 


\section{PENDAHULUAN}

Isu lingkungan telah menjadi isu masyarakat global yang melahirkan jaringan interaksi politik yang paling kompleks (Cornelis Lay, 2007). Mengutip dari Ginting, krisis yang dihadapi manusia modern merupakan akibat langsung dari pengelolaan lingkungan hidup yang non-etik, tanpa dilandasi nilai-nilai etika lingkungan atau moral lingkungan. Manusia kurang peduli pada norma-norma kehidupan atau mengganti norma-norma yang seharusnya dengan norma-norma ciptaan dan kepentingan sendiri. Manusia modern menghadapi alam hampir tanpa hati nurani (Ginting Suka, 2012). Orientasi hidup manusia modern yang cenderung materialistik dan hedonistik juga sangat berpengaruh. Kesalahan cara pandang atau pemahaman manusia tentang sistem lingkungannya, mempunyai andil yang sangat besar terhadap terjadinya kerusakan lingkungan yang terjadi dunia saat ini. Cara pandang dikotomis yang memandang alam sebagai bagian terpisah dari manusia dan paham antroposentris yang menganggap bahwa manusia adalah pusat dari sistem alam mempunyai peran besar terhadap terjadinya kerusakan lingkungan (White, 1967, Ravetz,1971, Sardar, 1984, Mansoor, 1993 dan Naess, 1993). Cara pandang antroposentris ini ternyata telah melahirkan perilaku yang eksploitatif dan tidak bertanggung jawab terhadap kelestarian sumberdaya alam dan lingkungannya (Ilyas Asaad, 20011:2).

Film adalah media representasi dan dianggap salah satu media yang efektif dalam menyampaikan pesan terhadap khalayak. Hal ini dikarenakan sifat film yang bersifat audiovisual dan mudah dicerna. Karena sifatnya yang mudah dicerna itu, film seringkali digunakan untuk merepresentasikan sebuah realitas (Indiawan, 2018:34). Hubungan antara film dan masyarakat selalu dipahami secara linear. Film selalu mempengaruhi dan membentuk masyarakat berdasarkan muatan pesan dibaliknya tanpa pernah berlaku sebaliknya. Film selalu merekam realitas yang tumbuh dan berkembang di masyarakat dan kemudian memproyeksikannya di atas layar (Sobur, 2009: 127).

Menurut Liz Blazer dalam bukunya Animated Storytelling (Simple Step for Creating Animation \& Motion Graphic (2016) film animasi adalah media pengisahan cerita tanpa batas. Seniman bisa membuat dunia menantang gravitasi, beralih dari faktual ke fantasi, dan membawa penonton ke tempat yang tidak pernah terbayangkan. Animasi merupakan salah satu karya desain komunikasi visual yang termasuk kedalam ruang lingkup komunikasi massa. Sama halnya dengan film, animasi juga dibangun dengan berbagai tanda. Hal tersebut bertujuan agar pesan yang disampaikan lebih mendalam kepada penontonnya. Terkait dengan penggunaan sistem tanda dalam sebuah animasi memunculkan makna-makna tertentu. Pemaknaan pada tanda tersebut bisa terlihat dari visualisasi penggunaan warna, gestur, dan karakter yang dimunculkan dalam animasi (Yasa Aulia, 2018). 
Princess Mononoke (1997) merupakan salah satu film animasi karya Hayao Miyazaki-salah satu animator terkenal Jepang pendiri dari Studio Ghibli, yang menampilkan mitos tradisional Jepang. Mengutip Rottentomatoes, Princess Mononoke adalah film animasi perang fantasi yang pada dasarnya adalah sebuah pernyataan tentang kerusakan ekologis yang disebabkan oleh kemajuan manusia, cerita ini mengikuti pertempuran antara putri Mononoke dan sebuah desa pertambangan ${ }^{1}$. Konflik yang terjadi disebabkan karena kerusakan lingkungan yang disebabkan oleh penggarapan hutan besar-besaran demi industrialisasi Tatara Ba (Kota Besi) yang dipimpin oleh Nona Eboshi membuat Nago-dewa babi penjaga hutan yang tinggal disana marah, lalu melakukan balas dendam sehingga Nago berubah menjadi Tatarigami (Iblis). Putri Mononoke alias San yang menganggap dirinya serigala mengabdi kepada Dewa Rusa dan melindungi hutan bersama ibunya Dewa Serigala melawan penindasan yang dilakukan Eboshi dan sekutunya. Pertarungan sengit San dan Nona Eboshi tidak bisa dihindari.

Film Princess Mononoke adalah ideologi dari Miyazaki sekaligus simbol kemarahan Miyazaki atas dominasi dan eksploitasi alam yang sama sekali tidak menghormati dewa. Seperti yang dikatakan Susan Napier (2018) di dalam penelitiannya Miyazaki World Life In Art, Putri Mononoke membuka babak baru dengan ambisius dan marah, serta

1

https://www.rottentomatoes.com/m/princess m ononoke_1999 16 Agustus 2021 mengungkapkan pandangan dunia sutradara yang semakin kompleks, memasang film perpaduan yang erat antara frustrasi, kebrutalan, spiritualitas animistik, dan harapan hati-hati bahwa Miyazaki telah diasah dalam karya manga/komik Nausicaä sebelumnya. Film Miyazaki menawarkan ruang lingkup mistis, penggambaran kekerasan dan lingkungan yang belum pernah terjadi sebelumnya. Inti dari film Mononoke adalah mengangkat isu lingkunga lewat pandangan dan etika para tokohnya terhadap lingkungan. Tokoh Putri Mononoke atau San menonjol dengan pandangan Deep Ecology-menjaga keseimbangan alam dengan melawan manusia yang menggangu dan mengusik hutan tempat dewa-dewa bersemayam. Tokoh Ashitraka yang memperlihatkan pandangan ekosentris yang menginginkan harmonisasi antara manusia dengan alam. Ada pula, Tokoh Nona Eboshi dan biksu Jiko-Bou serta para pengikutnya yang menginginkan keuntungan dari hutan dan dewa untuk ambisis pribadi. Eboshi dan Jiko-Bou menunjukkan etika Antroposentrisme yang memandang bahwa manusia merupakan pusat dari sistem alam semesta. Nilai tertinggi adalah manusia dan kepentingannya (Keraf, 2002:36). Pandangan Antroposentris inilah yang menjadi konflik dalam cerita film. Masalah-masalah tentang lingkungan dalam Princess Mononoke disajikan Hayao Miyazaki dengan latar waktu pada zaman Jepang kuno era Muromachi. Melalui film animasi ini, Hayao mengingatkan kembali kepada penonon terhadap kepercayaan para leluhur tentang kekuatan alam yang melebihi kuasa manusia sehingga 
membangkitkan rasa hormat penonton terhadap alam. Miyazaki berharap agar manusia dapat menghargai alam dan menghentikan eksploitasi alam secara berlebihan kemudian kembali hidup ke alam (Widiastuti, 2014). Princess Mononoke adalah karya Miyazaki yang bertahan dan relevan hingga saat ini karena isu-isu lingkungan, environmentalist, kapitalisme, tidak akan pernah berakhir pada zaman pasca modern saat ini.

\section{METODOLOGI}

Dalam semiotik Barthes, proses representasi berpusat pada makna denotasi, konotasi, dan mitos. Ia mencontohkan, ketika mempertimbangkan sebuah berita atau laporan, akan menjadi jelas bahwa tanda linguistik, visual dan jenis tanda lain mengenai bagaimana berita itu direpresentasikan (seperti tata letak, rubrikasi, dsb) tidaklah sesederhana mendenotasikan sesuatu hal, tetapi juga menciptakan tingkat konotasi yang dilampirkan pada tanda. Barthes menyebut fenomena ini membawa tanda dan konotasinya untuk membagi pesan tertentu sebagai penciptaan mitos. Barthes menyebut mitos sebagai rangkaian konsep yang saling berkaitan (Sudibyo,2001:245). Mitos adalah sistem komunikasi, sebab ia membawakan pesan. Maka itu, mitos bukanlah objek. Mitos bukan pula konsep ataupun suatu gagasan, melainkan suatu cara signifikasi, suatu bentuk. Lebih jauh lagi, mitos tidak ditentukan oleh objek ataupun materi (bahan) pesan yang disampaikan, melainkan oleh cara mitos disampaikan.
Mitos tidak hanya berupa pesan yang disampaikan dalam bentuk verbal (kata-kata lisan ataupun tulisan), namun juga dalam berbagai bentuk lain atau campuran antara bentuk verbal dan nonverbal. Misalnya dalam bentuk film, lukisan, fotografi, iklan, dan komik. Semuanya dapat digunakan untuk menyampaikan pesan. Mitos tidak bisa lepas dari masyarakat. Meskipun zaman berganti, mitos akan tetap ada menyesuaikan dirinya dengan perkembangan dan keadaan suatu periode dalam masyarakat. Mitos adalah bagaiman kebudayaan menjelaskan atau memahami beberapa aspek tentang realitas atau gejala alam. Mitos merupakan produk kelas sosial yang sudah mempunyai suatu dominasi. Mitos primitif, misalnya mengenai hidup dan mati, manusia dan dewa. Sedangkan mitos masa kini misalnya mengenai femininimitas, maskulinitas, ilmu pengetahuan dan kesuksesan (Fiske,1990:88)

Penelitian ini menggunakan pendekatan kualitatif yang bersifat induktif, yaitu peneliti membiarkan permasalahan-permasalahan muncul dari data atau dibiarkan terbuka untuk interpretasi. Data dihimpun dengan pengamatan yang seksama, mencangkup deskripsi dalam konteks yang mendetail disertai catatan-catatan hasil wawancara yang mendalam, serta hasil analisis dokumen dan catatancatatan. Penelitian kualitatif yang diteliti ini mempunyai dua tujuan utama, yaitu: 1) menggambarkan dan mengungkapkan (to describe and explore) dan 2) menggambarkan dan menjelaskan (to describe and explain). Berdasarkan tujuan yang ingin dicapai 
itulah maka penelitian kualitatif menggunakan instrument pengumpulan data yang sesuai dengan tujuannya (Sukmadinata, 2007:60). Pandangan subjektif dalam pendekatan kualitatif merupakan penciptaan makna dari hasil pengkajian tanda, realitas bukanlah suatu yang tetap dan terkait pada subjektifitasan manusia itu sendiri. Kriteria kualitas penelitian dari prespektif ini ialah otentitas, yakni sejauh mana temuan penelitian mencerminkan penghayatan subjek yang diteliti. Nilai, etika dan pilihan moral peneliti melekat dalam proses penelitian dan pemilihan masalah penelitian, tujuan penelitian, paradigma, teori, dan metode atau teknik analisis yang digunakan (Mulyana, 2006:14). Data kualitatif yang penulis kumpulkan dapat berupa kata-kata, kalimat atau narasi. Data yang diperoleh penulis melalui hasil pengamatan secara mendalam. Berdasarkan gambaran tersebut, penulis akan menganalisis dan memilah satu persatu adegan/scene yang berindikasikan penindasan alam dalam film Princess Mononoke. Proses analisis dilakukan secara deskriptif dan menggunakan metode analisis teori semiotika Roland Barthes dengan signifikasi makna denotasi dan konotasi yang sekaliguas menghasilkan mitos sehingga akan menarik kesimpulan mengenai bentuk penindasan alam dalam film Princess Mononoke.

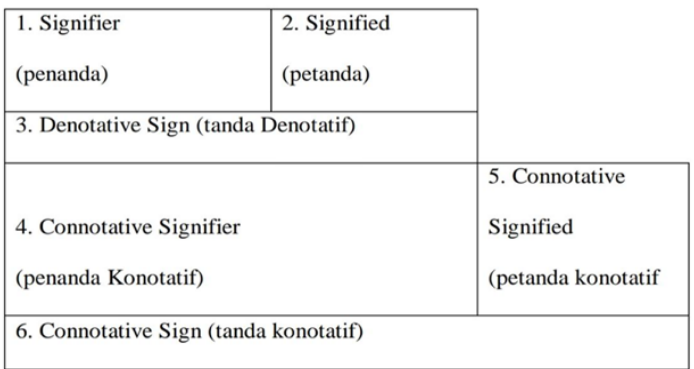

Gambar 1.

Peta Tanda Roland Barthes

Sumber: Paul Cobley \& Litza Jansz dalam Sobur (2006: 69).

Penelitian ini dilakukan dengan tahapan pertama, peneliti terlebih dahulu menonton film yang akan diteliti. Kedua, mencari tanda yang terdapat dalam film yang tindakan dan nilai-nilai yang dianggap sebagai penindasan terhadap alam di dalam film. Ketiga, tanda tersebut kemudian di analisis dengan menggunakan semiotika Roland Barthes. Barthes menjabarkan bahwa tanda terdiri dari penanda, petanda, Tanda Denotasi, Penanda Denotasi, Petanda Konotatif, Tanda Denotatif, Denotasi, Konotasi, dan Mitos. Terakhir, setelah mendapatkan mitos dari Princess Mononoke mengenai penindasan alam tersebut maka penulis melihat makna secara keseluruhan untuk mendapat kesimpulan.

\section{HASIL DAN PEMBAHASAN}




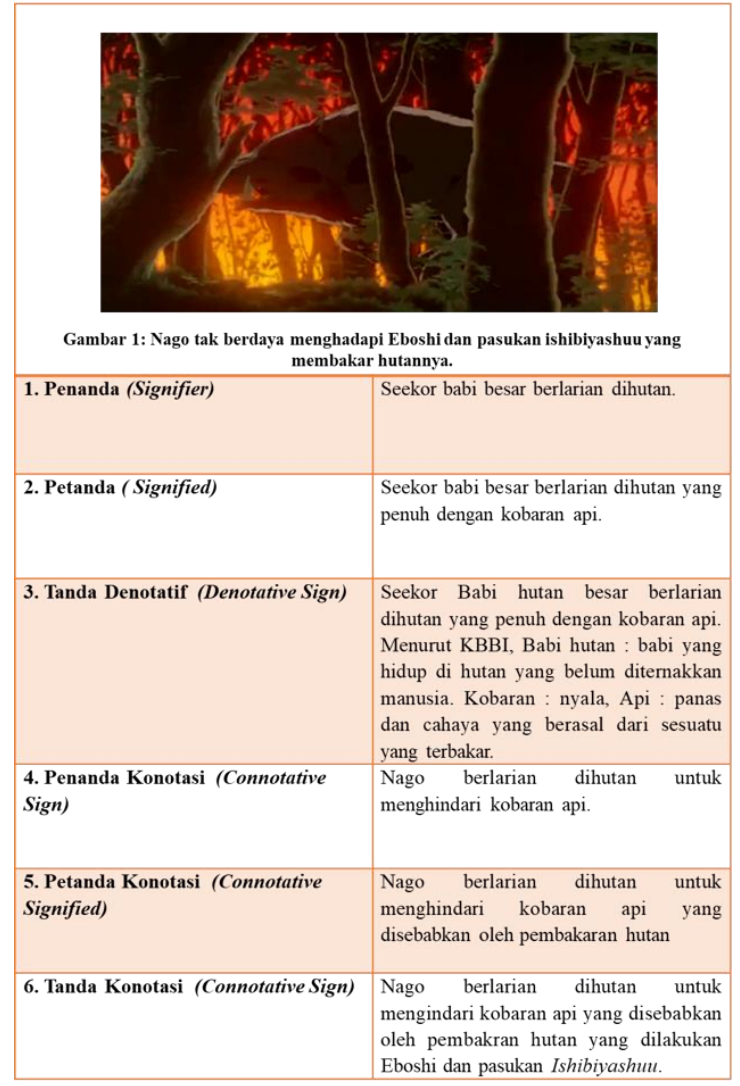

Denotasi: Siluet Babi besar yaitu Nago tengah berlarian sambil menghindari kobaran api yang menjalar hebat di seluruh hutan.

Konotasi: Nago tidak berdaya menghadapi kobrana api yang dihasilkan dari senjata ishibiya dari pasukan Eoshi.

Mitos: Siluet Nago yang berwarna cokelat kehitaman, berlair diantara kobaran api besar yang menjalar di seluruh hutan adalah bentuk rasa frustasi, kemarahan namun ada juga keputusasaan. Nago telah gagal dalam menjaga hutan yang menjadi rumah bagi klan babi hutan. Ia terpaksa berlari dan menghindari kobaran api untuk menyelamatkan dirinya. Dewa babi besar yang pada awal terlihat gagah sekarang nampak memprihatinkan dan tak berdaya ketika berhadapan dengan pasukan ishibiyashuu yang dipimpin oleh Eboshi. Selain itu Nago mendapat tembakan dari Ishibiya Eboshi sehingga bijih besi tertanam ditubuhnya.

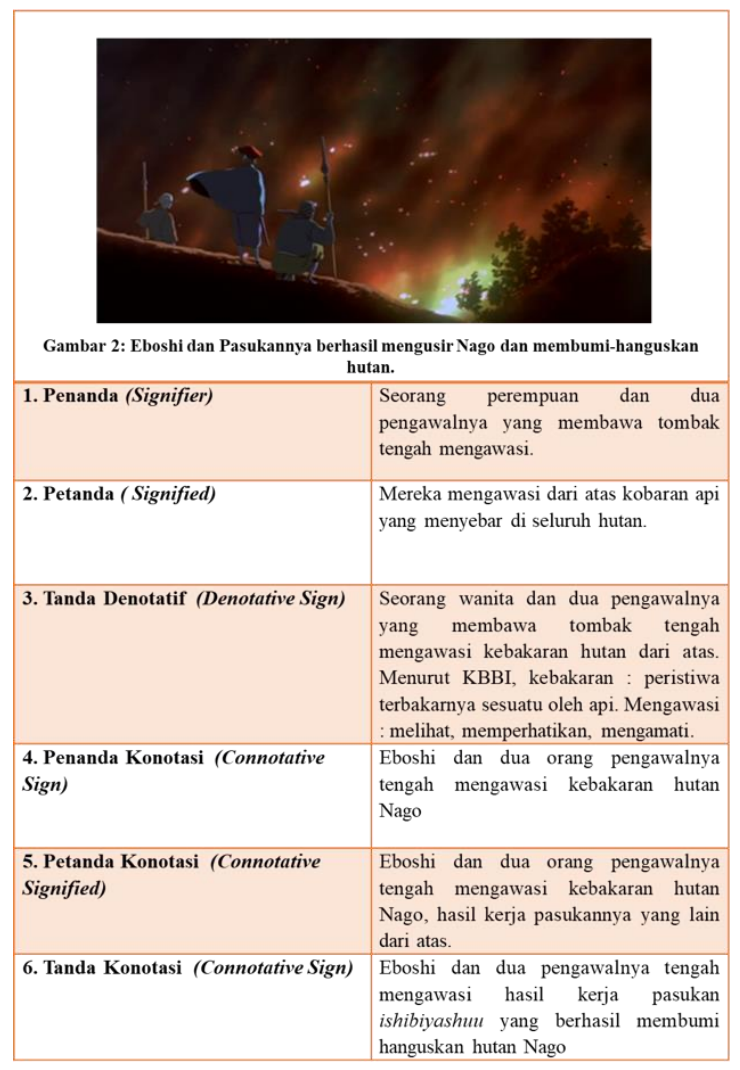

Denotasi: Eboshi dan dua orang pasukannya tengah memantau dari atas (sebuah dataran tinggi di hutan). Tampak hutan dipenuhi oleh api dan asap cokelat kemerahan bahkan kehitaman.

Konotasi: Eboshi berhasil menjalankan misinya untuk mengusir Nago dan para babi serta menguasai hutan tersebut.

Mitos: Eboshi dengan tegak berdiri dari atas (dataran tinggi) sampil memandangi kebakaran hutan dibawah sana menyiratkan bahwa wanita tersebut memantau setiap peristiwa 
yang berlangsung di hutan saat itu. Secara tak langsung Eboshi sudah merencanakan untuk membumi hanguskan hutan tersebut, dan hal tersebut dilakukan lebih awal karena adanya gangguan dari Nago. Dalam hal ini Eboshi juga menguji kekuatan dan jangkauan dari senjata Ishibiya-nya. Dan Eboshi berhasil menguji senjatanya tersebut dan misinya berjalan sesuai rencananya. Seluruh tumbuhan dan pohon hangus dan tak ada satupun yang terlewat oleh senjata tersebut.

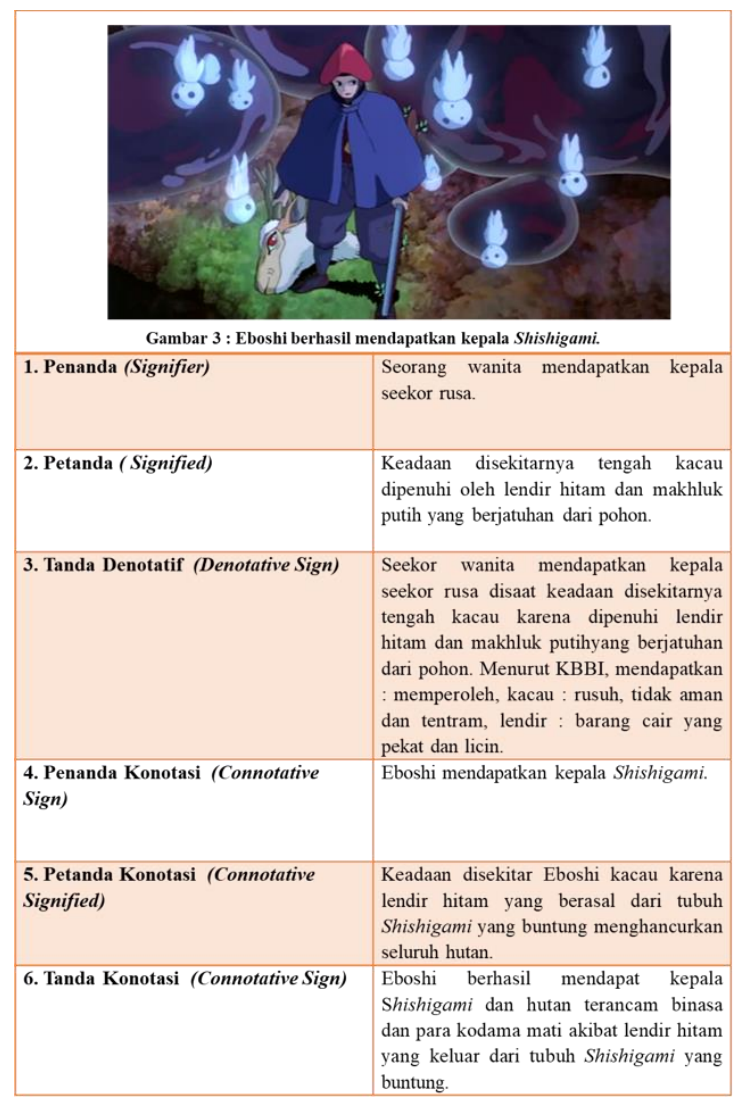

Denotasi: Eboshi mengambil penggalan kepala shishigami sambil menghindari lendir hitam. Ia segera memanggil JikoBou untuk menangkap kepala Shishigami. Disekitarnya, kodamakodama yang tinggal di pepohonan satu persatu mati dan berjatuhan karena terkena lendir hitam.

Konotasi: Bencana dan karma yang dirasakan manusia yang telah mengacaukan/menggangu roh/dewa yang menjaga kessimbangam alam.

Mitos: Eboshi segera mengamankan kepala Shishigami ditengah bencana lendir hitam yang merusak segalanya dan melemparkannya kepada Jiko-Bou. Dalam adegan dimana kepala Shishigami berpijak di atas rumput hijau dan subur, disana masih terdapat kehidupan. Kontras dengan keadaan sekeliling nya yang berwarna hitam kecokelatan yang mulai kering dan tandus. Hal ini menandakan bahwa kepala Shishigami masih hidup dan mengandung kekuatan menghidupkan. Tak luput juga, kodama-kodama yang jatuh berguguran dari atas pohon. Hal ini menunjukan bahwa lendir hitam itu bersifat sangat mematikan. Manusia, pepohonan, tanah, bahkan kodama, semua akan mati jka terkena lendir hitam ini. Warna hitam dalam kebudayaan Jepang bermakna nonmahkluk, misteri dan kemarahan. Hitam juga seringkali digunakan dalam ungkapan belasungkawa. Hitam juga menunjukkan orang yang berhati jahat. ${ }^{2}$ Ketika mati, Shishigami menunjukkan sifat-sifat yang berlawanan saat ketika ia hidup. Shishigamidikenal sebagai dewa Hutan Rusa sekaligus Dewa kematian yang bijaksana. Ia dapat menghidupkan dan mematikan mahkluk-terutama hewan dan tumbuhan. Namun setekah mati, lendir hitam-nya bersifat menghancurkan dan membinasakan semuanya.

\footnotetext{
2 https://www.color-meanings.com/ 9 Mei 2021
} 


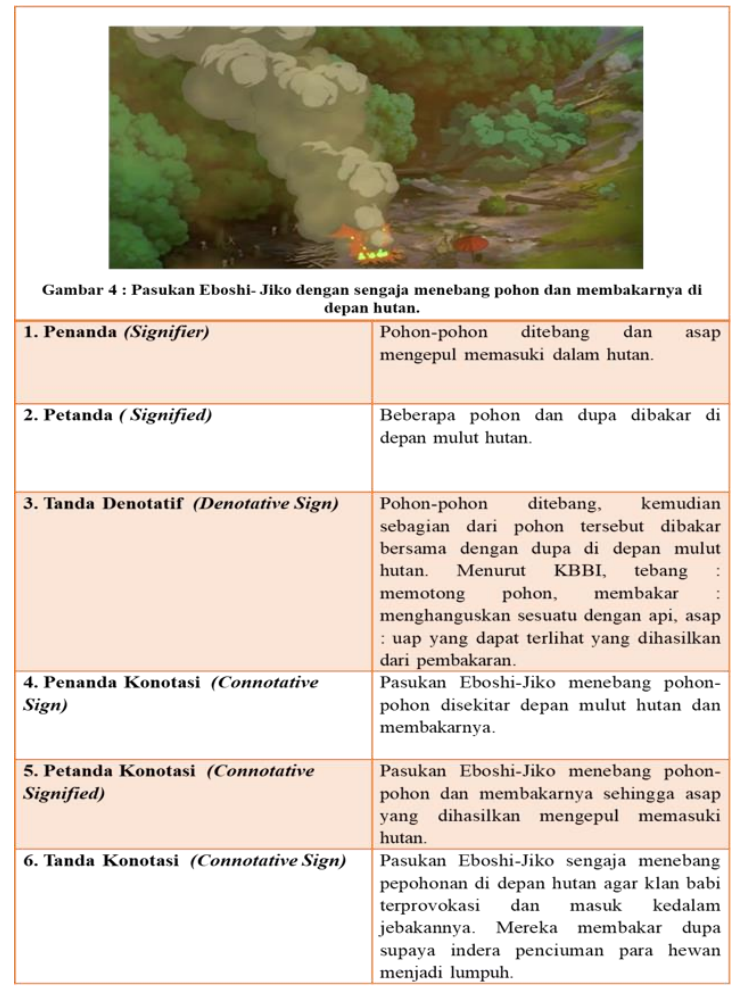

Denotasi: Pasukan Eboshi-Jiko menebang pepohonan di area mulut hutan dan membakarnya. Asap yang ditimbulkan menggantung sampai kelangit dan masuk ke area dalam hutan.

Konotasi: Pasukan Eboshi-Jiko memprovokasi klan babi agar masuk kedalam jebakan mereka.

Mitos: Penebangan dan pembakaran pohon-pohon di area mulut hutan bertujuan untuk memancing kemarahan klan babi, agar mereka keluar dari hutan menyerang kubu Eboshi-Jiko. Hal tersebut sudah menjadi strategi bagi Eboshi-Jiko agar babi-babi tersebut masuk kedalam perangkap mereka. Persiapan matang ini telah diperhitungkan oleh kubu pasukan Eboshi-Jiko. Mereka telah mempersiapkan segalanya untuk memburu Shishigami dan membantau para klan babi. Di benteng yang dibangun di area mulut hutan, mereka sengaja membakar semacam dupa yang asapnya sengaja di arahkan masuk kedalam hutan supaya dihirup oleh para bintang-khususnya para babi. Asap tersebut berbau busuk sekali dan melumpuhkan indera penciuman. Target mereka adalah Okkoto-dewa babi yang mereka tahu hawa Okkoto buta dan hanya mengandalkan indera penciumannya untuk "melihat" dunia. Mengetahui rencana tersebut, San dengan sukarela membantu Okkoto dan klan babi untk menjadi "mata" mereka.

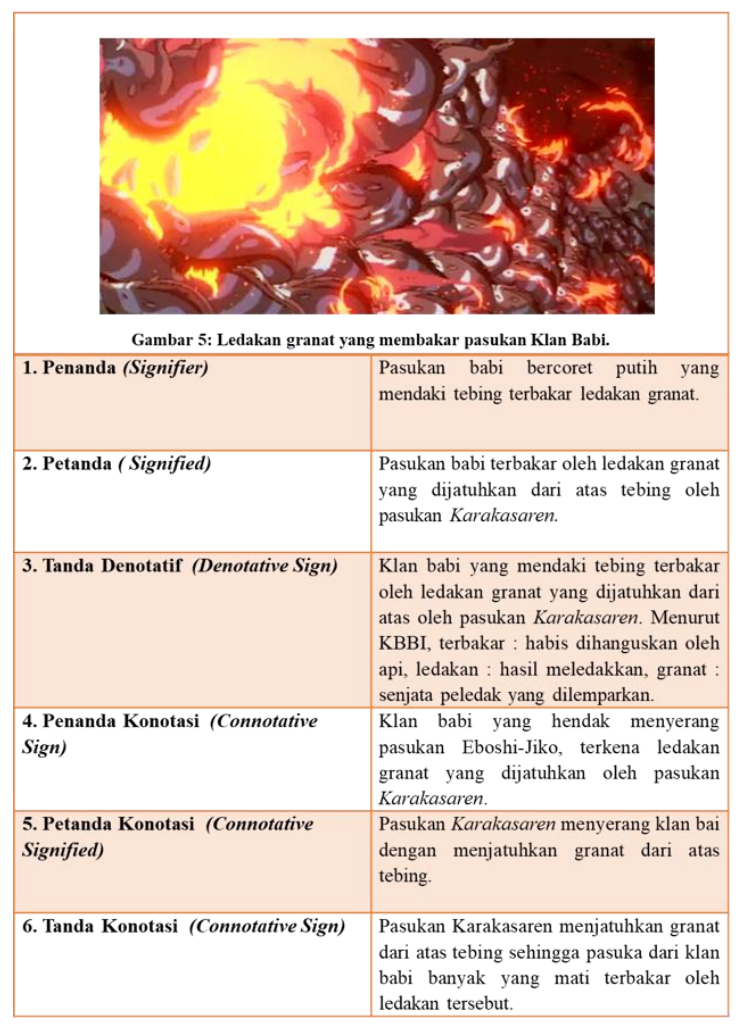

Denotasi: Granat pasukan Karakasaren meledak, mengenai pasukan klan babi yang sedang mendaki tebing. Banyak 
babi-babi yang runtuh, jatuh dari tebing akibat ledakan besar tersebut.

Konotasi: Klan babi tetap maju bertempur meskipun kekalahan hampir didepan mata.

Mitos: Granat-granat yang berjatuhan dari atas mengelinding masuk kedalam barisan pasukan klan babi secara terus menerus dan kemudian meledak dengan dahsyat. Hal tersebut membuat hampir seluruh barisan atas dan bawah para babi hancur dan mereka berjatuhan ke tanah. Hal ini menjadi kekalahan untuk klan babi dalam menghadapi pasukan Eboshi-Jiko

\section{KESIMPULAN}

Dalam Princess Mononoke, etika ekologi menjadi tema utama dalam ceritanya. Tema ekologi dan krisis alam yang diakibatkan ulah manusia diperlihatkan dan seringkali ditujukan oleh Miyazaki dalam karya-karya film animasinya. Princess Mononoke adalah karya yang mencerminkan pandangan keras Miyazaki terhadap krisis lingkungan. Tindakan dan etika Eboshi, Jiko-Bou dan para pengikut mereka adalah kekhawatiran Miyazaki terhadap manusia dan dunia yang mulai melupakan alam, tradisi dan terbuai dengan modernisasi sehingga menguburkan apa yang telah diwariskan oleh alam, budaya dan nenek moyang. Kemudian mitos dalam film yang relevan hingga saat ini adalah dampak perkembangan zaman yang serba menuntut dan maju membuat kebutuhan akan sumber daya alam bertambah dan tidak tercukupi. Dalam hal ini manusia mengeksploitasi alam dengan krisis moral dan tanpa etika, sehingga membuat para kami (dewa) marah. Etika antroposentrisme, kapitalisme, fasisme adalah bentukbentuk penindasan alam yang ditemukan dalam Princess Mononoke dan hal-hal tersebut menjadi sumber penyebab kerusakan alam. Dewa-dewa dan para binatang berubah menjadi beringas dan agresif, bahkan berubah menjadi Tatarigami (dewa kutukan/iblis) yang justru membahayakan alam dan manusia itu sendiri yang pada akhirnya konflik antara manusia dan dewa-dewa terjadi. Konflik antar manusia pun terjadi pada masa tersebut karena memperebutkan kekuasaan untuk medapatkan sumber daya alam yang bisa di eksploitasi. Dalam Princess Mononoke Miyazaki memperlihatkan bagaimana para tokohtokoh yang menganut etika antroposentrisme mengalami kekeliruan dalam memperlakukan alam dan etika tersebut menimbulkan berbagai bencana akibat kerusakan lingkungan yang akan mengancam kehidupan manusia itu sendiri. Sumber kesalahan cara pandang yang demikian ternyata terletak pada masalah moral manusia untuk mematuhi etika lingkungan.

\section{DAFTAR PUSTAKA}

Alex Sobur, (2006), Semiotika Komunikasi, Bandung: Remaja Rosdakarya Analisis Teks Media Suatu Pengantar untuk Analisa Wacana, Analisis Semiotik, dan Analisis framing, Bandung: PT Remaja Rosdakarya. 
Alex Sobur, 2009. Semiotika Komunikasi, Jakarta, Remaja Rosdakarya.

Asaad, Ilyas, 2011. "Teologi Lingkungan (Etika Pengelolaan Lingkungan dalam Perspektif Islam)", Deputi Komunikasi Lingkungan dan Pemberdayaan Masyarakat Kementerian Lingkungan Hidup Dan Majelis Lingkungan Hidup Pimpinan

Pusat Muhammadiyah.

Blazer, Liz. (2016). Animated Storytelling-Simple Steps for Creating Animation and Motion Graphic. United States of America: Peachpit Press.

Fachrul, Muhammad Alatas. 2018. "Representasi Tanggung Jawab Ketua Tim Pendaki Dalam Film "Everest" (Analisis Semiotika Roland Barthes)" Jurnal Pantarei Vol.2 No.1 2018

Fiske, John. 1990. Cultural and Communication Studies: Sebuah Pengantar Paling Komprehensif. Yogyakarta: Jalasutra.

Ginting, Suka. 2012. Teori Etika Lingkungan. Antroposentrisme, Ekofeminisme, Ekosentrisme. Denpasar: Udayana University Press.

Ida Ayu Widiastuti, 2014."Wacana Konflik Lingkungan Dalam Teks Film Animasi Mononoke Hime Karya Hayao Miyazaki" Tesis Universitas Udayana Denpasar.

Keraf, A. Sonny. 2002. Etika Lingkungan. Jakarta: Penerbit Buku Kompas.

Lay,Cornelis. 2007. "Nilai Strategis Isu Lingkungan dalam Politik
Indonesia", Jurnal Ilmu Sosial dan Ilmu Politik VOLUME 11, Nomor 2, November 2007 (153286).

Putri, Yasa Aulia. 2018. "Analisis Semiotika Visual Animasi Upin \& Ipin Episode "Ikhlas Dari Hati" Jurusan Seni Rupa Fakultas Bahasa Dan Seni Universitas Negeri Padang.

Mansoor, M, 1983. Environment and Values: The Islamic Perspective. Dalam Sardar, Z, The Touch of Midas,op.cit.

Mulyana, Deddy. 2006. Ilmu Komunikasi Suatu Pengantar. Bandung: Remaja Rosdakarya.

Naess, A. 1993. Ecology, Community and Lifestyle. Cambridge University Press, Cambridge.

Napier, Susan. 2018 "Miyazaki World Life In Art" Yale University Press.

Ravets, J.R, 1971. Scientific Knowledge and Its Social Problems, OUP Publication, London.

Sardar, Z, 1987. Masa Depan Islam. Terjemahan: Islamic Future, Penerbit Pustaka, Bandung.

Sudibyo, Agus. (2001). Politik Media dan Pertarungan Wacana. Yogyakarta: LKIS.

Sukmadinata, Nana Syaodih. 2017. Metode Penelitian Pendidikan. Bandung: Remaja Rosdakarya.

Wahjuwibowo, Indiawan. 2018. Semiotika Komunikasi Aplikasi Praktis Bagi Penelitian dan 
Skripsi Komunikasi Edisi 3. https://www.color-meanings.com/ Jakarta : Mitra Wacana Media.

https://tensai-indonesia.com/warnapenting-di-jepang

White, J.R, and Lynn, 1967, The https://en.wikipedia.org/wiki/Bo-hiya Historical Roots of Our Ecological Crisis. J. Science: 155; 1203-1207.

https://en.wikipedia.org/wiki/Fire arrow https://www.rottentomatoes.com/m/princ ess mononoke 1999

Internet 